\title{
Snowballs from the past
}

\author{
Martin Kennedy and colleagues searched the Australian outback for clues to the transition out of \\ Snowball Earth. The answer, as it turns out, was much closer to home.
}

What was the objective of the work at the beginning of the project?

We originally set out to try to understand the presence of a distinctive carbonate horizon that sharply overlies Neoproterozoic glacial deposits (formed $\sim 635$ million years ago) in basins around the world. Carbonates, often interpreted as warm-climate indicators, are not commonly associated with glacial deposits in the geological record. This horizon is particularly odd because it has a strongly negative carbon isotopic anomaly and contains very distinctive physical features. We believed the association suggested an abrupt change in carbon cycling leading to, or caused by, a rapid shift in climate with deposition of carbonate occurring during ice-sheet melting and global sealevel rise.

The physical and geochemical features are also similar to those reported from modern methane hydrates, and we began to wonder if the cap carbonate and the climate change might be related to destabilization of these hydrates and rapid warming from the greenhouse influence of methane. Although we found abundant evidence of methane influence we could not be sure whether the methane was causing warming or released by warming already underway.

Did you encounter any difficulties, for example, of a technical, human or administrative nature?

One of the more frustrating moments was the discovery that the four wheel drive did not work on our vehicle. Unfortunately, we discovered this after we had driven to the bottom of a steep valley in a very isolated part of the Flinders Ranges. The next day was spent

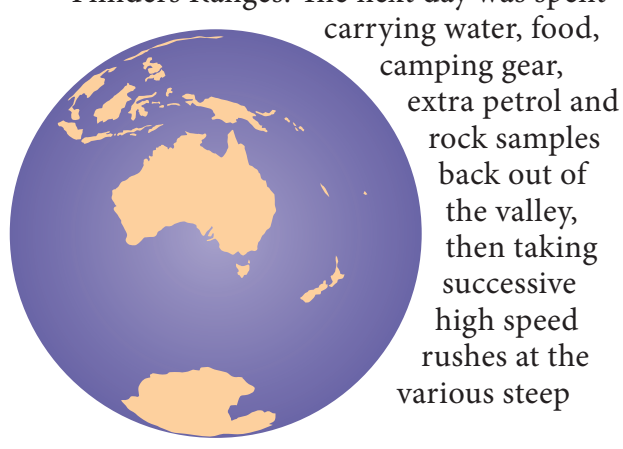

E10

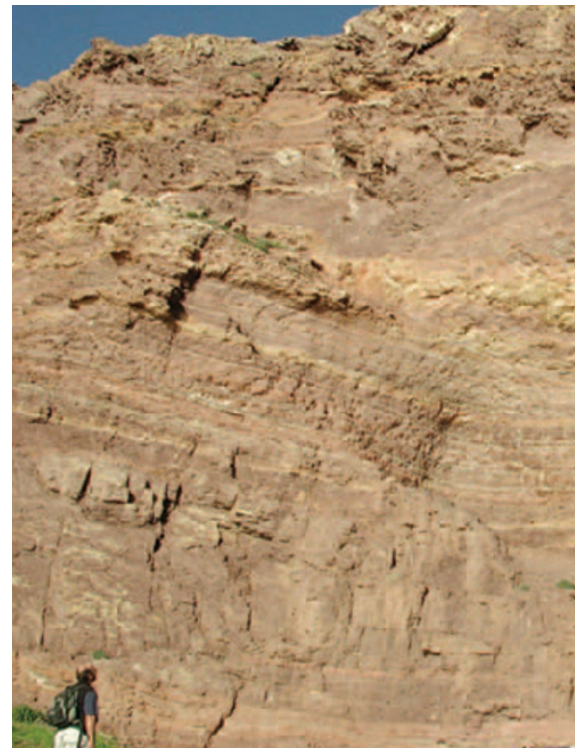

The cliff that revealed methane seep features.

sections of the hill to get the vehicle up out and out again.

Why did you choose this particular location for the fieldwork?

Although Neoproterozoic glacial deposits occur in many basins around the world, South Australia is home to the rock unit that defines the Ediacaran period (635 to 542 million years ago), which lies at the base of the cap carbonate horizon we were interested in. The rock unit is well exposed in many areas in outback Australia. The location described in this study, however, was not in the remote outback, but was found in a spectacular coastal cliff exposure that was our last stop on the way home. Ironically, after a whole field season focused on isolated and demanding field sites, this exposure, in suburban Adelaide, lies beneath the house of one of the authors! We had walked past this outcrop innumerable times, but it took the experience gained by looking at many modern and ancient seep structures elsewhere to break through the over-familiarity and recognize the distinctive shape and geometry.
What sorts of data or samples were you after?

We wanted to sample sediments that recorded disruption by the meltdown of methane hydrates and the distinctive stable isotope finger print methane oxidation can leave behind. In the location of our fieldwork, we found some exceptionally preserved tidal sediments that had previously been identified as low-latitude deposits $\left(<15^{\circ}\right)$.

What was the highlight of the expedition? The day after our initial recognition of what we thought could be seeps, we returned to the outcrop to find that the evidence supporting the methane seep interpretation was still compelling. In addition, we found more and even better evidence when we recognized the paleoenvironmental evidence and the timing relations of the seep carbonates. We were equally thrilled when the laboratory results showed that the samples strongly supported the interpretation.

Did the trip give you any ideas for future research projects?

These results alerted us to a potential component of the climate system that lay dormant throughout the ancient ice age, but once activated, provided a strong positive feedback driving what is likely to be the most extreme global warming event in the Earth's history. Next we would like to quantify the biogeochemical effects on the cycles of other elements such as oxygen and sulphate using numerical models. To do this we will need timing constraints on the duration of the methane release relative to deglaciation. Our next focus will thus be stratigraphic field studies of cap carbonates in central Australia where we can better constrain the timing of events during deglaciation.

This is the Backstory to the work by Martin Kennedy and colleagues, discussed in the News \& Views article on page 351 of this issue. 